\title{
Evaluating aeration and stirring effects to improve itaconic acid production from glucose using Aspergillus terreus
}

\author{
Nándor Nemestóthy · Péter Bakonyi [D · Péter Komáromy • Katalin Bélafi-Bakó
}

Received: 5 September 2019/Accepted: 10 October 2019/Published online: 15 October 2019

(C) The Author(s) 2019

\begin{abstract}
The effects of the bioreactor conditions, in particular the mode and intensity of aeration and mixing were studied on itaconic acid (IA) fermentation efficiency by Aspergillus terreus strain from glucose substrate. IA was produced in batch system by systematically varying the oxygen content of the aeration gas (from 21 to 31.5 vol\% $\mathrm{O}_{2}$ ) and the stirring rate (from 150 to $600 \mathrm{rpm}$ ). The data were analyzed kinetically to characterize the behavior of the process, and besides, the performances were evaluated comparatively with the literature. It turned out that the operation of the bioreactor with either the higher inlet $\mathrm{O}_{2}$ concentration $\left(31.5 \mathrm{vol} \% \mathrm{O}_{2}\right.$ ) or faster stirring (600 rpm) could enhance biological IA generation the most, resulting in yield and volumetric productivity of $0.31 \mathrm{~g} \mathrm{IA} / \mathrm{g}$ glucose and $0.32 \mathrm{~g} \mathrm{IA} / \mathrm{g}$ glucose and $3.15 \mathrm{~g} \mathrm{IA} / \mathrm{L}$ day and $4.26 \mathrm{~g} \mathrm{IA} / \mathrm{L}$ day, respectively. Overall, the significance of fermentation settings was shown in this work regarding IA production catalyzed by $A$. terreus and notable advances could be realized by adjusting the aeration and stirring towards an optimal combination.
\end{abstract}

N. Nemestóthy · P. Bakonyi $(\bowtie) \cdot$ P. Komáromy ·

K. Bélafi-Bakó

Research Institute on Bioengineering, Membrane

Technology and Energetics, University of Pannonia,

Egyetem ut 10, 8200 Veszprém, Hungary

e-mail: bakonyip@almos.uni-pannon.hu
Keywords Aeration - Itaconic acid fermentation . Kinetic modeling · Process enhancement $\cdot$ Stirring

\section{Introduction}

Whole-cell biocatalysis has been widely-employed to produce various organic components, including itaconic acid (IA) (Zhao et al. 2018). Nowadays, larger volume synthesis of IA takes place through fermentation, involving the assistance of fungal biological catalysts, in most cases strains such as Aspergillus terreus. In various reports, it was found that the efficiency of the process-in terms of the technologically most important IA yield and productivitycould be affected by the conditions provided in the fermenter unit. Actually, the variables that have been confirmed to take strong influence on bioreactor performance during IA production cover the quality of the medium and type of substrate, temperature, $\mathrm{pH}$, aeration and stirring (Mondala 2015; Hevekerl et al. 2014; Karaffa et al. 2015; Kolláth et al. 2019; Molnár et al. 2018; Shin et al. 2013).

Recently, as part of systematic investigation, Nemestóthy et al. (2019) and Komáromy et al. (2019) showed that A. terreus NRRL 1960 was able to generate IA on glucose-based broth in submerged fermentation and gave positive feedback concerning the substantial role of adequate $\mathrm{pH}$ control strategy 
(Komáromy et al. 2019). By comparing the results of these studies to the literature, it could be drawn they were typically in agreement with achievements of other relevant research works (Kautola et al. 1985; Kuenz et al. 2012; Riscaldati et al. 2000). However, it should be underlined that in those previous papers from our research group (Komáromy et al. 2019; Nemestóthy et al. 2019), the experiments were carried out under fixed mixing and air supply circumstances. This means in other words that their influences on IA production capacity of A. terreus have not yet been addressed in our systems, although, as concluded before, proper management of these variables can enable maneuvering the process towards additional improvements (Garcia-Ochoa and Gomez 2009; Molnár et al. 2018).

Thus, in the current research, to take another step forward, IA fermentation was intended in laboratoryscale bioreactors by A. terreus on glucose substrate under varied operating regimes to enlighten the impact of aeration and stirring. Particularly, the effect of inlet air composition by adjusting its $\mathrm{O}_{2}$ content was studied in addition to that of stirring rate in the batch fermenter. The obtained data were after that analyzed and compared to the literature in order to evaluate the findings of the investigation.

\section{Materials and methods}

Inoculum and bioreactor set-up

The culture of filamentous fungi, A. terreus NRRL 1960 , was used thoroughly in this work to produce itaconic acid. Strain maintenance and conditions for inoculum preparation in terms of broth composition, temperature, etc. were the same as detailed in our previous paper (Komáromy et al. 2019; Nemestóthy et al. 2019). To test the effect of varied aeration and stirring circumstances on IA production capability of the A. terreus strain, autoclavable Sartorius Stedim BIOSTAT ${ }^{\circledR}$ Bplus bioreactor system (with $1.5 \mathrm{~L}$ working volume, $10(\mathrm{v} / \mathrm{v}) \%$ inoculation ratio) was deployed (https://fenix-sd.com/content/user_files/ File/Biostat_B_plus.pdf, accessed on 11. 07. 2019), employing two Rushton turbines on the central mixing shaft. The IA fermentation tests were performed under batch operating mode with the following (initial) media composition: $120 \mathrm{~g} / \mathrm{L}$ glucose, $0.1 \mathrm{~g} / \mathrm{L}$
$\mathrm{KH}_{2} \mathrm{PO}_{4}, 3 \mathrm{~g} / \mathrm{L} \mathrm{NH}_{4} \mathrm{NO}_{3}, 1 \mathrm{~g} / \mathrm{L} \mathrm{MgSO}_{4} \times 7 \mathrm{H}_{2} \mathrm{O}$, $5 \mathrm{~g} / \mathrm{L} \mathrm{CaCl}{ }_{2} \times 2 \mathrm{H}_{2} \mathrm{O}, 1.67 \times 10^{-3} \mathrm{~g} / \mathrm{L} \mathrm{FeCl}_{3} \times 6$ $\mathrm{H}_{2} \mathrm{O}, 8 \times 10^{-3} \mathrm{~g} / \mathrm{L} \mathrm{ZnSO}_{4} \times 7 \mathrm{H}_{2} \mathrm{O}, 15 \times 10^{-3} \mathrm{~g} / \mathrm{L}$ $\mathrm{CuSO}_{4} \times 7 \mathrm{H}_{2} \mathrm{O}$, adopted from the recent study of Komáromy et al. (2019).

The experimental plan is shown in Table 1. As it can be seen, the impact of inlet aeration gas $\mathrm{O}_{2}$ content on IA production was investigated using air (21 vol\% $\mathrm{O}_{2}$ ) as well as $5 \%$ and $50 \% \mathrm{O}_{2}$-enriched mixtures (relative to the air, resulting in 22.05 and 31.5 vol.\% $\mathrm{O}_{2}$, respectively). All gases were supplied from gas cylinders. Gas mixtures with higher $\mathrm{O}_{2}$ portion had been prepared using compressed (synthetic) air and oxygen $(99.995 \%$ purity) (both purchased from Messer Hungarogáz Kft, Hungary) and final composition was checked and verified by GC method. Apart from that, as indicated in Table 1, the effect of stirring rate on IA fermentation efficiency was sought by varying it in the range of 150-600 rpm, employing air for this set of measurements. The $\mathrm{pH}$ and temperature were continuously controlled at $3 \pm 0.1$ and $37^{\circ} \mathrm{C}$ for all the fermentations, respectively (Komáromy et al. 2019).

Kinetic analysis of batch itaconic acid fermentations and assessment of process performance

The modified Gompertz-model is widely-accepted to extract useful kinetic parameters of batch fermentation and was applied with success in our previous papers on itaconic acid production (Komáromy et al. 2019; Nemestóthy et al. 2019). In general, this model (Eq. 1) with S-shape can be beneficial for the evaluation of microbiologically-catalyzed bioprocess taken into account the actual progress curves (Park et al. 2019). For the particular case of itaconic acid formation, based on the experimental data of Fig. 1, it can be applied in the following form (Eq. 1):

$I A(t)=P \exp \{-\exp [(l-t)+1]\}$

where IA (t), t (h), P (g/L), $\mathrm{R}_{\mathrm{m}}(\mathrm{g} / \mathrm{L}-\mathrm{h}), \lambda(\mathrm{h})$ and $e$ represent the (i) experimental itaconic acid titer as the function of time (ii) actual process time (iii) itaconic acid titer potential (iv) maximal itaconic acid (titer) production rate (v) lag-phase time and (vi) the Euler's number, respectively. The best model fitting could be achieved by using the Solver tool of MS Excel and the least-squares regression method. 
Table 1 The experimental plan performed in this study

\begin{tabular}{llll}
\hline Setting & Aeration gas flow rate $(\mathrm{L} / \mathrm{min})$ & $\mathrm{O}_{2}$ content of aeration gas $($ vol\%) & Stirring rate (rpm) \\
\hline 1 (Control) & - & - & - \\
2 (Reference) & 2 & 21 & 150 \\
3 & 2 & 22.05 & 150 \\
4 & 2 & 31.5 & 150 \\
5 & 2 & 21 & 600 \\
\hline
\end{tabular}

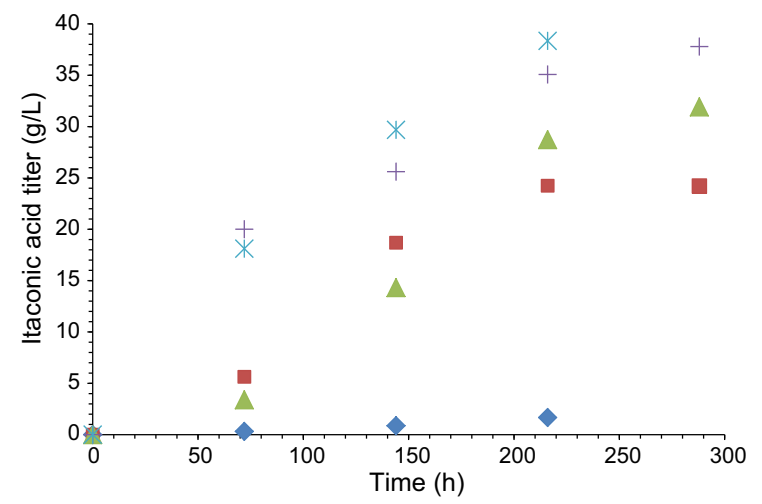

Fig. 1 Time profiles for itaconic acid fermentation under various aeriation and mixing conditions. Symbols are according to Table 1: diamonds—setting 1 (control); squares-setting 2 (reference); triangles—setting 3; crosses — setting 4; asteriskssetting 5

Besides, two major indices to reveal the effectiveness of IA production are the volumetric productivity (mass of IA normalized to the bioreactor working volume and the processing time in the unit of $\mathrm{g} I \mathrm{~A} / \mathrm{L}$ day) and the yield (mass of IA relative to the mass of substrate ensured initially in the unit of $\mathrm{g}$ IA/g glucose added $_{\text {), }}$, which were therefore considered to evaluate and compare the results thoroughly similar to our previous research (Komáromy et al. 2019; Nemestóthy et al. 2019). To determine itaconic acid concentrations in samples taken at various periods of the fermentations, HPLC method as detailed by Komáromy et al. (2019) and Nemestóthy et al. (2019) was applied.

\section{Results}

Aeration and mixing intensity are crucial factors for aerobic bioprocess optimization (Garcia-Ochoa and Gomez 2009). As the production of IA is obligatory aerobic, it requires the maintenance of sufficient oxygen supply in the whole working volume of the bioreactor, influenced by the oxygen mass transfer conditions (Shin et al. 2013). For instance, Molnár et al. (2018) proved recently that the dissolved oxygen concentration as high as $30 \%$ of saturation level notably determined the fermentation profile with $A$. terreus, particularly in terms of IA rate and yield.

In general, using mechanically-stirred bioreactors as in this study too for submerged fermentation of IA by $A$. terreus, the gas-to-liquid phase oxygen mass transfer rate is significantly dependent-besides several other parameters-on (i) how much oxygen gas is fed per unit of time and (ii) how the $\mathrm{O}_{2}$ is subsequently dispersed thoroughly (Garcia-Ochoa and Gomez 2009). The former can be affected by the volumetric flow rate of the inlet gas and its $\mathrm{O}_{2}$ content, while the latter relies strongly on the rate of stirring and were therefore examined in this work following the experimental plan in Table 1. The IA formation results are summarized in Table 2 and visualized in Fig. 1.

As it can be noticed, the control test lacking continuous aeration and mixing produced only a negligible amount of IA, which was in agreement with the expectations and indeed pointed to the substantial role of these process variables. Compared

Table 2 Experimental itaconic acid concentrations obtained under the fermentation conditions listed in Table 1

\begin{tabular}{llllll}
\hline Time (h) & 1 (Control) & 2 (Reference) & 3 & 4 & 5 \\
\hline 0 & 0 & 0 & 0 & 0 & 0 \\
72 & 0.31 & 5.63 & 3.4 & 20.01 & 18.11 \\
144 & 0.87 & 18.69 & 14.32 & 25.61 & 29.68 \\
216 & 1.67 & 24.23 & 28.73 & 35.07 & 38.34 \\
288 & & 24.21 & 31.92 & 37.79 & \\
\hline
\end{tabular}


Fig. 2 Experimental values (diamonds) versus model data (squares) using the modified Gompertzequation for itaconic acid production
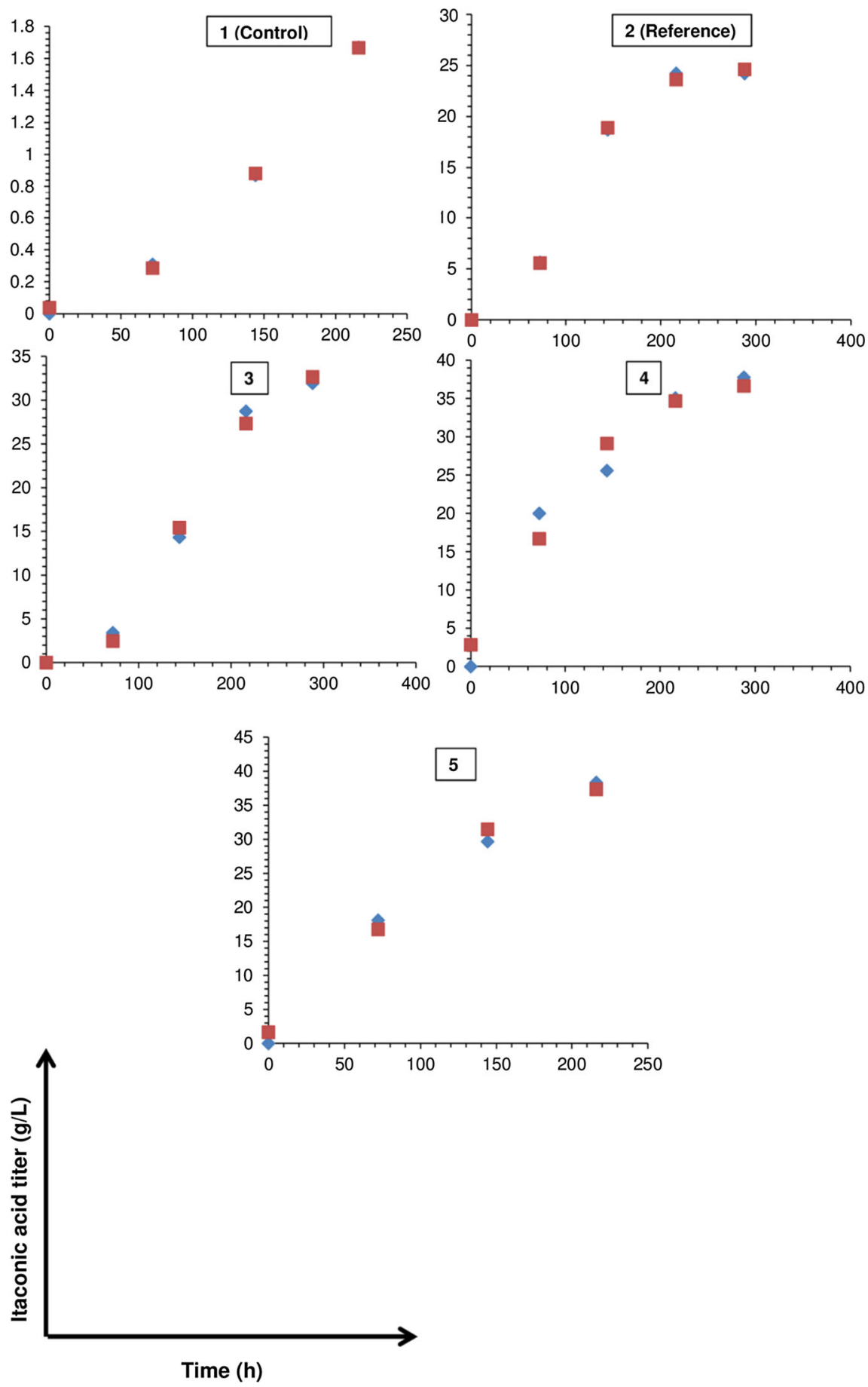

to that, the fermentation carried out under reference settings (air, $150 \mathrm{rpm}$ ) was remarkably more efficient, yielding approximately $24 \mathrm{~g} / \mathrm{L}$ IA concentration after 12 days. Furthermore, by assessing Fig. 1, it is clear that changing the air to $\mathrm{O}_{2}$-enriched aeration gas led to considerable enhancement. In this set of experiments focusing on the impact of aeration, the highest IA titer $(37.8 \mathrm{~g} / \mathrm{L})$ was obtained with the gas containing $31.5 \mathrm{vol} \% \mathrm{O}_{2}$. Interestingly, when the effect of stirring rate was sought in separate measurements by 
Table 3 Results of the kinetic evaluation conducted on the experimental results summarized in Table 2

\begin{tabular}{lccccc}
\hline Model parameter & 1 (Control) & 2 (Reference) & 3 & 4 & 5 \\
\hline $\mathrm{P}(\mathrm{g} / \mathrm{L})$ & 3.8 & 24.9 & 35.4 & 37.6 & 39.8 \\
$\mathrm{Rm}(\mathrm{g} / \mathrm{L}-\mathrm{h})$ & 0.01 & 0.22 & 0.21 & 0.22 & 0.27 \\
$\lambda(\mathrm{h})$ & 66.1 & 46.7 & 70.8 & -3.17 & 8.8 \\
\hline
\end{tabular}

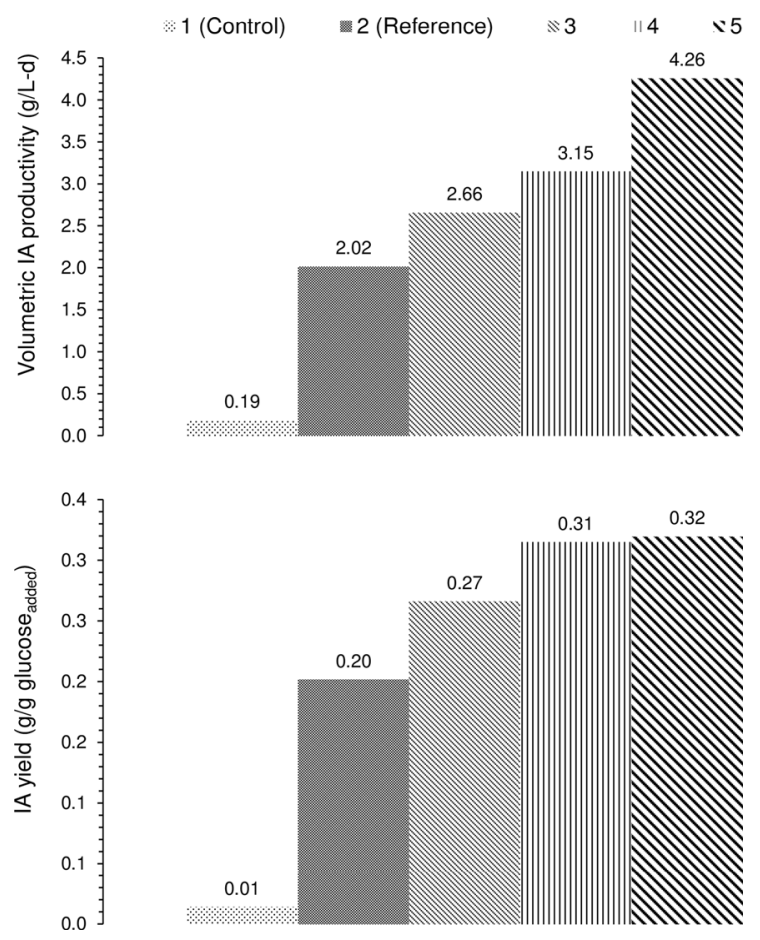

Fig. 3 The attainable itaconic acid volumetric productivities and yields under the experimental circumstances specified in Table 1

increasing to $600 \mathrm{rpm}$ from $150 \mathrm{rpm}$, the final IA concentration was quite similar, $38.3 \mathrm{~g} / \mathrm{L}$.

By subjecting the results in Table 2 to kinetic evaluation by the modified Gompertz-model (Sect. 2.2.), a good correlation of real and model data was found (Fig. 2) with marginal differences between maximal projected and experimental IA titers appearing in Tables 3 and 2 an, respectively, e.g. 39.8 versus $38.3 \mathrm{~g} / \mathrm{L}$ (setting 5), 37.6 versus $37.8 \mathrm{~g} / \mathrm{L}$ (setting 4), etc. Moreover, the explicit impact of the varied fermentation conditions on maximal itaconic acid generation rate and lag-phase time could be noted. Considering $\mathrm{P}, \mathrm{Rm}$ and $\lambda$ altogether to rank the fermentations (Komáromy et al. 2019), settings 4 (aeration gas with highest $\mathrm{O}_{2}$ content) and 5 (most intense mixing) were the most promising thanks to greater IA production capacities, rates and shortened adaptation periods.

In addition to kinetic results, the productivity and yield were computed and illustrated in Fig. 3 to assess the bioreactor performance. In our previous study $1.27 \mathrm{~g} / \mathrm{L}$ day and $0.12 \mathrm{~g} \mathrm{IA} / \mathrm{g}$ glucose were achieved at $\mathrm{pH} 3,37{ }^{\circ} \mathrm{C}$ (as in this work) at $1.5 \mathrm{~L}$ air/L min aeration and relatively gentle agitation (Komáromy et al. 2019). Nevertheless, in the present investigation, $4.26 \mathrm{~g} / \mathrm{L}$ day and $0.32 \mathrm{~g} \mathrm{IA} / \mathrm{g}$ glucose (setting 5, Table 1) and $3.15 \mathrm{~g} / \mathrm{L}$ day and $0.31 \mathrm{~g} \mathrm{IA} / \mathrm{g}$ glucose (setting 4, Table 1) could be realized. Hence, it seems that by properly improving the oxygen supplementation and mixing conditions it was truly possible to further increase the IA production performance by $A$. terreus, serving as the key-objective of this work. Further benchmarking with the already existing literature infers that the results obtained here coincide well with those presented by other scientist, covering the wider range of $2.88-12.24 \mathrm{~g} \mathrm{IA} / \mathrm{L}$ day and 0.21-0.62 g IA/g glucose (Kautola et al. 1985; Kuenz et al. 2012; Riscaldati et al. 2000).

\section{Discussion}

The IA yield and productivity data reported in this paper are plotted in Fig. 4 to imply that for an efficient process, it is beneficial if both of these measures are enhanced at the same time (Kumar et al. 2015).

The data within the green loop of Fig. 4-in agreement with the above discussion-illustrate that the potential of A. terreus to generate IA could be improved either by providing better aeration or stirring. Although in this research these two effects were distinguished, it is reasonably presumed that by combining them it will be possible to maintain better hydrodynamics and target the zone of further 
Fig. 4 The correlation of itaconic acid volumetric productivity and yield obtained in this work
Enhanced yield and productivity (proper $\mathrm{O}_{2}$ supply and mixing)

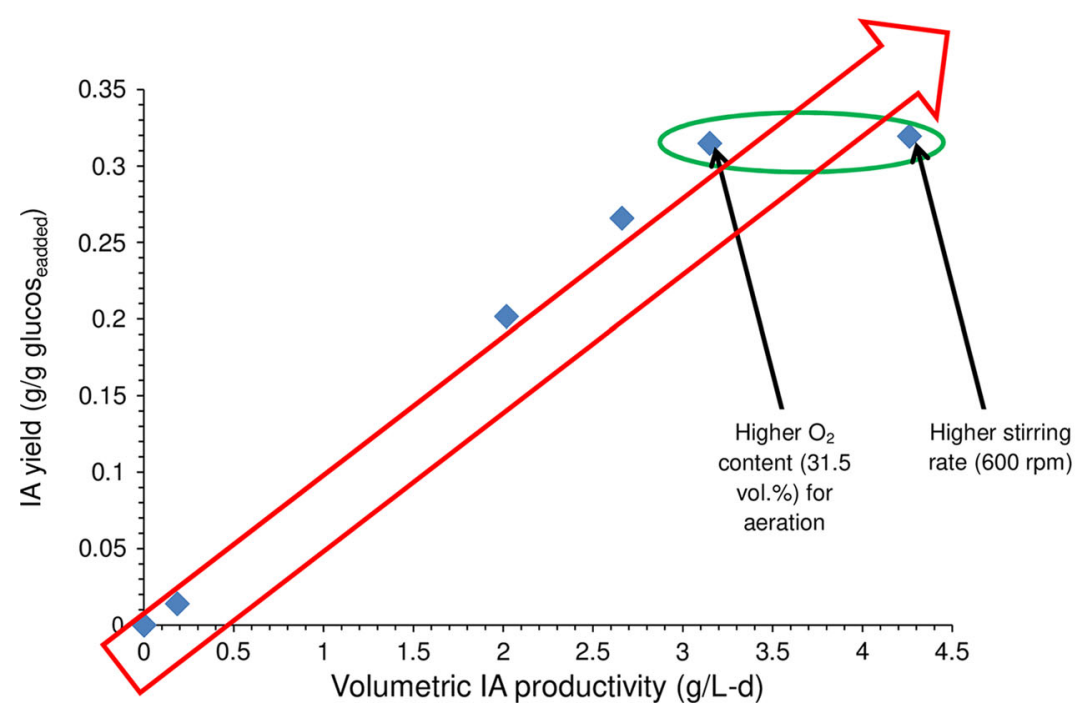

augmented yield and productivity (red arrow, Fig. 4). As in the aerobic bioreactor unit, the factor that takes both aeration and stirring conditions into account is the so-called $\mathrm{K}_{\mathrm{L}} \mathrm{a}$ (oxygen mass transfer coefficient) (Garcia-Ochoa and Gomez 2009), the next study in our research sequence ought to deal with the examination of $\mathrm{K}_{\mathrm{L}} \mathrm{a}$ in assisting IA production. For instance, Shin et al. (2013) documented the increment of $\mathrm{K}_{\mathrm{L}} \mathrm{a}$ in response to more vigorous mixing (from 100 to $300 \mathrm{rpm})$ and larger air loading $(0.5-1.5 \mathrm{~L} / \mathrm{L} \mathrm{min})$ for pilot-scale IA fermenter with A. terreus. Nevertheless, it is to stress that simultaneous setting of aeration and mixing for favorable $\mathrm{K}_{\mathrm{L}} \mathrm{a}$ mustn't threaten the growth of A. terreus since the appearance of extreme shearing forces may damage its filamentous network and deteriorate biosynthesis of IA consequently.

In other words, the successful production in the bioreactor is largely dependent on higher oxygen mass transfer rate and tolerable shearing forces by microorganisms, especially in case of fungi such as A. terreus as pellet/filament morphology may undergo notable changes under varied stirring and aeration regimes (Casas López et al. 2005; Gao et al. 2014). Hence, morphological studies are to be performed and discussed for further elucidation of findings obtained in our fungal bioreactor.

\section{Conclusions}

This work focused on the influence of aeration and stirring during IA production from glucose by $A$. terreus NRRL 1960. Kinetic analysis accomplished via the modified Gompertz-model verified the unambiguous effect of these two fermentation variables on IA production performance. It was found that intensified mixing and increased concentration of oxygen in the aeration gas both were in aid of realizing process enhancement. The results indicate the need for optimizing the oxygen mass transfer in the bioreactor, which can be attempted in the future (follow-up) work via the more in-depth study of $\mathrm{K}_{\mathrm{L}}$ a where morphological changes of fungal network are also considered for elaborating the correlations between biomass growth characteristics and metabolite production.

Acknowledgements Open access funding provided by University of Pannonia (PE). This research was supported by the National Research, Development and Innovation Fund Project NKFIH OTKA K 119940 entitled "Study on the electrochemical effects of bioproduct separation by electrodialysis".

Data availability All data generated or analyzed during this study are included in this published article.

\section{Compliance with ethical standards}

Conflict of interest The authors declare that they have no conflict of interest. 
Research involving human participants or animals This article does not contain any studies with human participants or animals performed by any of the authors.

Open Access This article is distributed under the terms of the Creative Commons Attribution 4.0 International License (http:// creativecommons.org/licenses/by/4.0/), which permits unrestricted use, distribution, and reproduction in any medium, provided you give appropriate credit to the original author(s) and the source, provide a link to the Creative Commons license, and indicate if changes were made.

\section{References}

Casas López JL, Sánchez Pérez JA, Fernández Sevilla JM et al (2005) Pellet morphology, culture rheology and lovastatin production in cultures of Aspergillus terreus. J Biotechnol 116:61-77. https://doi.org/10.1016/j.jbiotec.2004.10.005

Gao Q, Liu J, Liu L (2014) Relationship between morphology and itaconic acid production by Aspergillus terreus. J Microbiol Biotechnol 24:168-176. https://doi.org/10.4014/ jmb.1303.03093

Garcia-Ochoa F, Gomez E (2009) Bioreactor scale-up and oxygen transfer rate in microbial processes: An overview. Biotechnol Adv 27:153-176. https://doi.org/10.1016/j. biotechadv.2008.10.006

Hevekerl A, Kuenz A, Vorlop KD (2014) Influence of the pH on the itaconic acid production with Aspergillus terreus. Appl Microbiol Biotechnol 98:10005-10012. https://doi.org/10. 1007/s00253-014-6047-2

Karaffa L, Díaz R, Papp B et al (2015) A deficiency of manganese ions in the presence of high sugar concentrations is the critical parameter for achieving high yields of itaconic acid by Aspergillus terreus. Appl Microbiol Biotechnol 99:7937-7944. https://doi.org/10.1007/s00253-015-67356

Kautola H, Vahvaselka M, Linko YY et al (1985) Itaconic acid production by immobilized Aspergillus terreus from xylose and glucose. Biotechnol Lett 7:167-172. https://doi. org/10.1007/BF01027812

Kolláth IS, Molnár ÁP, Soós Á et al (2019) Manganese deficiency is required for high itaconic acid production from D-xylose in Aspergillus terreus. Front Microbiol 10:1589. https://doi.org/10.3389/fmicb.2019.01589

Komáromy P, Bakonyi P, Kucska A et al (2019) Optimized pH and its control strategy lead to enhanced itaconic acid fermentation by Aspergillus terreus on glucose substrate.
Fermentation 5:31. https://doi.org/10.3390/fermentation 5020031

Kuenz A, Gallenmüller Y, Willke T et al (2012) Microbial production of itaconic acid: developing a stable platform for high product concentrations. Appl Microbiol Biotechnol 96:1209-1216. https://doi.org/10.1007/s00253-0124221-y

Kumar G, Bakonyi P, Periyasamy S et al (2015) Lignocellulose biohydrogen: practical challenges and recent progress. Renew Sustain Energy Rev 44:728-737. https://doi.org/10. 1016/j.rser.2015.01.042

Molnár ÁP, Németh Z, Kolláth IS et al (2018) High oxygen tension increases itaconic acid accumulation, glucose consumption, and the expression and activity of alternative oxidase in Aspergillus terreus. Appl Microbiol Biotechnol 102:8799-8808. https://doi.org/10.1007/s00253-018-932 5-6

Mondala AH (2015) Direct fungal fermentation of lignocellulosic biomass into itaconic, fumaric, and malic acids: current and future prospects. J Ind Microbiol Biotechnol 42:487-506. https://doi.org/10.1007/s10295-014-1575-4

Nemestóthy N, Komáromy P, Bakonyi P et al (2019) Carbohydrate to itaconic acid conversion by Aspergillus terreus and the evaluation of process monitoring based on the measurement of $\mathrm{CO}_{2}$. Waste Biomass Valor (in press). https://doi.org/10.1007/s12649-019-00729-3

Park SG, Rhee C, Shin SG et al (2019) Methanogenesis stimulation and inhibition for the production of different target electrobiofuels in microbial electrolysis cells through an on-demand control strategy using the coenzyme $\mathrm{M}$ and 2-bromoethanesulfonate. Environ Int 131:105006. https:// doi.org/10.1016/j.envint.2019.105006

Riscaldati E, Moresi M, Federici F et al (2000) Effect of pH and stirring rate on itaconate production by Aspergillus terreus. J Biotechnol 83:219-230. https://doi.org/10.1016/S01681656(00)00322-9

Shin WS, Lee D, Kim S et al (2013) Application of scale-up criterion of constant oxygen mass transfer coefficient ( $\mathrm{kLa}$ ) for production of itaconic acid in a $50 \mathrm{~L}$ pilot-scale fermentor by fungal cells of Aspergillus terreus. J Microbiol Biotechnol 23:1445-1453. https://doi.org/10.4014/jmb. 1307.07084

Zhao M, Lu X, Zong H, Li J, Zhuge B (2018) Itaconic acid production in microorganisms. Biotechnol Lett 40:455-464. https://doi.org/10.1007/s10529-017-2500-5

Publisher's Note Springer Nature remains neutral with regard to jurisdictional claims in published maps and institutional affiliations. 